\title{
P-wave dispersion and its relationship with the severity of the disease in patients with stable coronary artery disease
}

\author{
Fatih Akin'1, Inci Firatli², Fahrettin Katkat'2, Tevfik Gurmen², Burak Ayca², \\ Muhsin Kalyoncuoglu' ${ }^{2}$, Okay Abaci ${ }^{2}$, Mustafa Sari ${ }^{2}$, Murat Ersanli'2, \\ Serdar Kucukoglu², Zerrin Yigit ${ }^{2}$ \\ ${ }^{1}$ Department of Cardiology, Mugla Sitki Kocman University School of Medicine, Mugla, Turkey; \\ ${ }^{2}$ Department of Cardiology, Istanbul University Institute of Cardiology, Istanbul, Turkey
}

\begin{abstract}
OBJECTIVE: P- wave dispersion (PD) is an indicator of inhomogeneous and discontinuous propagation of sinus impulses. In the present study we aimed to investigate the PD and its association with the severity of the disease. in patients with stable coronary artery disease.
\end{abstract}

METHODS: We prospectively analyzed 60 subjects with coronary artery disease (CAD) and 25 subjects with normal coronary angiograms (control group). The maximum and minimum P-wave duration and PD were measured from the 12-lead surface electrocardiograms. The CAD severity was assessed by the severity score (Gensini score) and the number of vessels involved (vessel score).

RESULTS: P max was longer in CAD group compared with the control group $(p<0.001)$. PD was greater in the CAD group, compared with the control group $(p<0.001)$. However, $P$ min did not differ between the two groups. In bi-variate correlation, increased PD was correlated with presence of diabetes mellitus $(r=0.316, p=0.014)$, smoking $(r=0.348, p=0.006)$, left ventricular ejection fraction $(r=-0.372, p=0.003)$, vessel score $(r=0.848, p=0.001)$, and Gensini score $(r=0.825, p=0.001)$. Multiple linear regression analysis showed that PD was independently associ $\neg$ ated with vessel score $((3=0.139, p=0.002)$ and Gensini score $((3=0.132, p=0.007)$.

CONCLUSION: PD was greater in patients with CAD than in controls and it was associated with CAD severity. Key words: Coronary artery disease; gensini score; stable angina pectoris; P-wave dispersion.

$\mathrm{P}$ wave dispersion (PD) may be defined as the difference between the longest and shortest $\mathrm{P}$ wave duration recorded from different multiple surface electrocardiographic leads $[1,2]$. Prolonged $\mathrm{P}$ wave duration and increased PD have been showed to be associated with an increased risk for atrial fibrillation (AF) which is characterized by inhomogeneous and discontinuous atrial conduction [3]. A 
growing evidence shows that people who are higher PD have higher risks for several cardiovascular-related conditions such as diabetes mellitus, obesity, hypertension, peripheral vascular disease, and myocardial infarction [4-7]. Furthermore, PD has been found to be to associated with an increase in carotid intima-media thickness and inflammatory markers such as C-reactive protein [8]. However, there are very few studies that have shown the relationship between stable coronary artery disease and $\mathrm{P}$ wave dispersion [9]. Therefore, in the present study we aimed to determine the association of $\mathrm{PD}$ with the severity of coronary artery disease (CAD) in patients with stable coronary artery disease.

\section{MATERIALS AND METHODS}

\section{Study population}

A total of 85 ( 30 women 55 men) consecutive patients routinely referred to coronary angiography for stable angina pectoris were included in the study after the following exclusions: any kind of rhythm abnormailities that could have interfered with $\mathrm{P}$ - wave analysis (AF, freguent atrial and ventriculer beats, pacemaker rhythm), acute coronary syndromes, valvular heart disease, serum electrolyte disturbances, abnormal thyroid function, pulmonary hypertension, cardiomyopathies, use of any antiarrhythmic drug, history of myocardial infarction, percutaneus coronary intervention, and cardiac surgery. Entry criteria included chest pain or other symptoms suggestive of myocardial ischemia whe clinically indicated coronary angiography. Detailed physical examination, electrocardiogram and echocardiogram were performed on all patients. The clinical risk factors for the patients such as age, gender, hypertension (HT), diabetes mellitus (DM), history of hyperlipidemia, and smoking status were noted.

Patients were divided into 4 groups based on their extent of angiographic coronary artery disease. Patients with normal coronary arteries were labeled as normal group (25 patients), 22 patients with signficant obstruction in 1 major epicardial artery were considered as having 1 vessel disease, 26 patients with significant obstruction in 2 major epicardial arteries were included in the 2 vessel disease group, finally 12 patients with significant obstruction in 3 major epicardial arteries were enrolled in the 3 vessel disease group. Hypertension was defined based on blood pressure 140/90 mm Hg or greater, and a history of antihypertensive drug use. DM was defined as fasting blood glucose $\geq 126 \mathrm{mg} / \mathrm{dl}$ on two occasions or being on treatment. The local ethics committee approved the study protocol. All demographic and clinical data were collected prospectively.

\section{Electrocardiography}

A 12- lead surface electrocardiogram (ECG) was obtained from each patient while in supine position. Recordings were acquired at a paper speed of $50 \mathrm{~mm} / \mathrm{s}$, with $1 \mathrm{mV} / \mathrm{cm}$ standardization. Two in-vestigators without knowledge of the clinical status of the patients manually measured the maximum and minimum $\mathrm{P}$-wave duration and PD. To improve accuracy we used calipers and magnifying lenses. ECG with measurable P-waves in over than 10-leads were included in the analysis. The onset of $\mathrm{P}$-wave was defined as the junction between the end of the P-wave deflection and the ofset of the Pwave as the junction between the end of the $\mathrm{P}$-wave deflection and the isoelectric line. We calculated $\mathrm{P}$ maximum $(\mathrm{P} \max )$ and $\mathrm{P}$ minimum $(\mathrm{P} \min )$ and their diferences were defined as PD.

\section{Echocardiographic measurement}

Echocardiographic measurements were performed by using a $2.5 \mathrm{mHz}$ probe with Acuson Sequa echocardiographic device (Siemens, USA). LV dimensions were generally measured with $2 \mathrm{D}$-guided $\mathrm{M}$-mode from the parasternal projections, using a leading edge to leading edge convention. The left atrium and the left ventricle diameters, left ventricular ejection fraction (LVEF), and the presence of mitral insufficiency were evaluated.

\section{Coronary Angiography}

Coronary angiography was performed using the standard Judkins technique through femoral artery access. The angiographic characteristics, which included lesion location and percentage stenosis, of all coronary lesions in the index coronary angiogram 
were obtained by throughly reviewing the angiogram. Angiographic analysis was carried out by two experienced cardiologists who were blinded to the study protocol. The severity of CAD severity was assessed by using the vessel and Gensini score. Vessel score was the number of vessels with a significant stenosis (>\%50). Scores ranged from 0 to 3, depending on the number of vessels involved [10]. We also used Gensini scoring system [11]. According to this method we defined narrowing of the lumen of coronary arteries as 1 for $1-25 \%$ stenosis, 2 for $26-50 \%$ stenosis, 4 for $51-75 \%$ stenosis, 8 for $76-90 \%$ stenosis, 16 for $91-99 \%$ stenosis and 32 for total occlusion. Then the score is multiplied by a factor that shows the significance of the lesion's location. The multiplication factor for the left main system lesion is 5 . It is 2.5 for proximal left anterior descending artery (LAD) and proximal circumflex artery $(\mathrm{Cx})$ lesions, 1.5 for a mid-LAD lesion, and 1 for distal LAD, $\mathrm{mid} /$ distal $\mathrm{CX}$ and right coronary artery lesions. The multiplication factor for any other branch is 0.5 .

\section{Statistical analyses}

SPSS-15.0 software (SPSS Inc., Chicago, IL) was used for all statistical analyses. Baseline demographic data are presented as mean \pm SD for continuous variables and frequancies for discrete variables. Comparison of parametric values between the 2 groups was performed by means of an independent samples t-test. Categorical variables were assessed by using chi-square test. Correlation between $\mathrm{P}$ wave measurements and angiographic, clinical, and echocardiographic variables were assessed by Pearson correlation coefficient. To ascertain the independent contribution to PD multiple linear regression analysis was made. A two-tailed value of $\mathrm{p}<0.05$ was considered statistically significant.

\section{RESULTS}

The clinical, echocardiographical and electrocardiographic characteristics of the cases in group 1 and group 2 are shown in Table 1 . There was no difference in comparison of groups with regard to age, hypertension, diabetes and smoking. Male patients were more numerous in the CAD group. Pmax, PD and EF were also higher in the CAD group. We divided the study population into 4 subgroups according to vessel scores. $\mathrm{P}$-wave measurements are given in Table

TABLE 1. Baseline clinical, echocardiographical and electrocardiographic characteristics of the study population

\begin{tabular}{|c|c|c|c|c|c|c|c|}
\hline & \multicolumn{3}{|c|}{ CAD group $(n=60)$} & \multicolumn{3}{|c|}{ Control group $(n=25)$} & \multirow[t]{2}{*}{$\mathrm{p}$} \\
\hline & $\mathrm{n}$ & $\%$ & Mean \pm SD & $\mathrm{n}$ & $\%$ & Mean \pm SD & \\
\hline Age (years) & & & $56.98 \pm 10.1$ & & & $53.16 \pm 9.6$ & NS \\
\hline Male gender & 44 & 73.3 & & 11 & 44 & & 0.01 \\
\hline Hypertension & 35 & 58.3 & & 12 & 48 & & NS \\
\hline Diabetes & 25 & 41.6 & & 11 & 44 & & NS \\
\hline Smoking & 27 & 45 & & 8 & 32 & & NS \\
\hline LAD (mm) & & & $3.44 \pm 0.30$ & & & $3.50 \pm 0.33$ & NS \\
\hline LVESD (mm) & & & $2.66 \pm 0.88$ & & & $2.68 \pm 0.10$ & NS \\
\hline LVEDD (mm) & & & $5.24 \pm 0.23$ & & & $5.18 \pm 0.26$ & NS \\
\hline LVEF & & & $55 \pm 5.49$ & & & $58.8 \pm 3.74$ & 0.002 \\
\hline Pmax (ms) & & & $102.22 \pm 10.47$ & & & $84.28 \pm 6.36$ & $<0.001$ \\
\hline Pmin (ms) & & & $54.72 \pm 9.53$ & & & $53.76 \pm 7.24$ & NS \\
\hline $\mathrm{PD}(\mathrm{ms})$ & & & $47.53 \pm 8.49$ & & & $30.52 \pm 3.25$ & $<0.001$ \\
\hline
\end{tabular}

CAD: coronary Artery Disease; LV: Left Ventricle; EDD: End-Diastolic Dimension; ESD: End-Systolic Dimension; EF: Ejection Fraction; LAD: Left Atrial Diameter; P max: P maximum; P min: P minimum; PD: P Dispersion; NS: Non-Significant. 
TABLE2. Comparison of $\mathrm{P}$ wave measurements of the groups according to vessel score

\begin{tabular}{lccccccc}
$\begin{array}{c}\text { Control } \\
(\text { Group 1 }) \\
(n=25)\end{array}$ & $\begin{array}{c}\text { Single vessel } \\
(\text { Group 2) } \\
(n=22)\end{array}$ & $\begin{array}{c}\text { Double vessel } \\
(\text { Group 3) } \\
(n=26)\end{array}$ & $\begin{array}{c}\text { Triple vessel } \\
(\text { Group 4) } \\
(n=12)\end{array}$ & P1 & P2 & P3 \\
\hline Pmax & $84 \pm 6$ & $101 \pm 8$ & $100 \pm 10$ & $110 \pm 10$ & $<0.001$ & NS & $<0.013$ \\
Pmin & $53 \pm 7$ & $57 \pm 9$ & $51 \pm 9$ & $54 \pm 9$ & NS & NS & NS \\
PD & $30 \pm 3$ & $42 \pm 4$ & $46 \pm 7$ & $58 \pm 10$ & $<0.001$ & 0.039 & 0.001 \\
\hline
\end{tabular}

P1: comparision of variables between group 1 and 2; P2: comparision of variables between group 2 and 3; P3: comparision of variables between group 2 and 4; P max: P maximum; P min: P minimum; PD: P Dispersion.

2. Although P max was significantly higher in Groups 2, 3 and 4, no difference was determined between Groups 1 and 2. PD was greater in all patient groups compared with the controls for all comparisons. The relationship between $\mathrm{PD}$, and clinical, and echocardiographic characteristics in patients with CAD is shown in Table 3. In CAD group, PD was related to diabetes, smoking and EF $(p=0.014, p=0.006$, $\mathrm{p}=0.003)$ but not related to other clinical and echocardiographic characteristics (Table 3). Pmax and PD were related to vessel and Gensini scores in patients

TABLE 3. The relationship between $P$ wave dispersion, and clinical and echocardiographic characteristics in patients with coronary artery disease

\begin{tabular}{lcc} 
& $r$ & $p$ \\
\hline Age & -0.004 & 0.974 \\
Gender & 0.052 & 0.695 \\
Hypertension & 0.017 & 0.895 \\
Diabetes & 0.316 & 0.014 \\
Smoking & 0.348 & 0.006 \\
LAD & -0.068 & 0.605 \\
LVS & -0.102 & 0.440 \\
LVD & -0.016 & 0.901 \\
Mild MR & 0.071 & 0.591 \\
LVEF & -0.372 & 0.003
\end{tabular}

LV: Left Ventricle; EDD: End-Diastolic Dimension; ESD: End-Systolic Dimension; EF: Ejection Fraction; LAD: Left Atrial Diameter; MR: Mitral Regurgitation with CAD (Table 4). In multivariate logistic regression analysis, increased PD was found to be independently associated with vessel $(\beta=4.139, p=0.002)$ and Gensini score $(\beta=0.132, p=0.007)$.

\section{DISCUSSION}

Our study showed, increased $\mathrm{P}$ wave duration and $\mathrm{PD}$ was related to the extent and severity of CAD in stable coronary artery disease patients. Similarly, increased PD has been observed to be associated with coronary artery disease severity [9].

$\mathrm{AF}$ is the most common cardiac rhythm abnor-

TABLE 4. The relationship between $P$ wave measurements and Gensini and vessel scores in patients with coronary artery disease

\begin{tabular}{ccc} 
& Vessel score & Gensini score \\
\hline Pmax & & \\
$r$ & 0.668 & 0.615 \\
$p$ & 0.001 & 0.001 \\
Pmin & & \\
$r$ & -0.080 & -0.128 \\
$p$ & 0.465 & 0.249 \\
PD & & \\
$r$ & 0.848 & 0.825 \\
p & 0.001 & 0.001 \\
\hline
\end{tabular}

$\mathrm{P}$ max: $\mathrm{P}$ maximum; $\mathrm{P}$ min: $\mathrm{P}$ minimum; $\mathrm{PD}$ : $\mathrm{P}$ wave dispersion 
mality and its incidence was $0.6 \%$ in the Coronary Artery Surgery Study (CASS) registry [12]. It was demonstrated that atrial fibrillation is a predictor of survival. Interatrial conduction delays have been shown to be implicated in initiating and maintaining $\mathrm{AF}[13-15]$.

Another mechanism for increased PD may be the increase in collagen fiber deposition in the cardiac interstitium. It was reported that PD was associated with inhomogeneus and discontinuous propogation of sinus impulses [16]. Electrocardiographic markers of abnormal atrial conduction, such as PD, $\mathrm{P}$ maximum, and $\mathrm{P}$ minumum, may be influenced by myocardial ischemia. Atrial fibrosis due to myocardial ischemia may prolong PD [17-20]. Previous studies have demonstrated that atrial ischemia is implicated in the pathogenesis of AF [21, 22].

Dilaveris et al, reported that myocardial ischemia prolongs $\mathrm{PD}$ in 95 patients with documented CAD and Özmen et al. confirmed this feature in patients with angioplasty induced myocardial ischemia $[23,24]$. PD has also been found to be associated with carotid atherosclerosis [8]. In addition, it has been shown that $\mathrm{P}$-wave dispersion is increased in coronary slow- flow phenomenon [25].

Ischemia- induced inhomogeneous and discontinuous atrial conduction may be related to increased P maximum and PD [26]. Reduced blood flow due to coronary atherosclerosis may contribute to the development of tissue injury and fibrosis [27]. Another explanation for this is that ischemia causes renin angiotensin system activation $[28,29]$. The regional fibrosis in the atrial wall, due to chronic ischemia could cause different atrial conductions leading to increased PD in surface ECGs.

Another pathophysiological explanation for increased $\mathrm{P}$-wave duration and dispersion in CAD may be autonomic tone associated with CAD. Tükek et al.[30] reported that the autonomic tone changes may prolong PD. Increased serum catecholamine levels may cause atrial fibrosis and heterogeneus conduction properties.

It was reported that PD was significantly associated with LV diastolic dysfunction [31]. Ischemic left ventriculer dysfunction may increase left atrial pressure, and might another fundamental causes of increased $\mathrm{P}$ wave duration and $\mathrm{PD}$ in patients with CAD compared to control subjects [32]. Atrial strain, which is a sugnificant factor in the pathophysiology of AF together with ischemia- induced hetergeneous atrial conduction, may results an increase in $\mathrm{P}$ wave duration and PD. Yilmaz et al. [9] found no significant association between $\mathrm{P}$ min and coronary artery disease severity. Similarly, in our study there was no significant association between $P$ min and Gensini and vessel scores.

There were some limitations in our study. The major limitation of our study is the small number of patients included in the study. For evaluation of ECG results we did not use the high-resolution computer software program. Previous studies have found a low error of the measurement of PD on paper printed ECGs, contrarily other studies reported that manual PD measurement on paper printed ECGs obtained at a standard signal size may effect the accuracy and reproducibility of the results $[33,34]$.

In conclusion, our results suggest that there is a considerable association between increased PD and the severity of CAD.

Conflict of Interest: No conflict of interest was declared by the authors.

Financial Disclosure: The authors declared that this study has received no financial support.

\section{REFERENCES}

1. Dilaveris PE, Gialafos EJ, Andrikopoulos GK, Richter DJ, Papanikolaou V, Poralis K, et al. Clinical and electrocardiographic predictors of recurrent atrial fibrillation. Pacing Clin Electrophysiol 2000;23:352-8. CrossRef

2. Dilaveris PE, Gialafos EJ, Sideris SK, Theopistou AM, Andrikopoulos GK, Kyriakidis M, et al. Simple electrocardiographic markers for the prediction of paroxysmal idiopathic atrial fibrillation. Am Heart J 1998;135:733-8. CrossRef

3. Dilaveris PE, Gialafos JE. P-wave dispersion: a novel predictor of paroxysmal atrial fibrillation. Ann Noninvasive Electrocardiol 2001;6:159-65. CrossRef

4. Yazici M, Ozdemir K, Altunkeser BB, Kayrak M, Duzenli MA, Vatankulu MA, et al. The effect of diabetes mellitus on the Pwave dispersion. Circ J 2007;71:880-3. CrossRef

5. Liu T, Fu Z, Korantzopoulos P, Zhang X, Wang S, Li G. Effect of obesity on p-wave parameters in a Chinese population. Ann 
Noninvasive Electrocardiol 2010;15:259-63. CrossRef

6. Cagirci G, Cay S, Karakurt O, Eryasar N, Acikel S, Dogan M, et al. $\mathrm{P}$-wave dispersion increases in prehypertension. Blood Press 2009;18:51-4. CrossRef

7. Karabag T, Dogan SM, Aydin M, Sayin MR, Buyukuysal C, Gudul NE, et al. The value of $\mathrm{P}$ wave dispersion in predicting reperfusion and infarct related artery patency in acute anterior myocardial infarction. Clin Invest Med 2012;35:E12-9.

8. Ozuğuz U, Ergün G, Işık S, Gökay F, Tütüncü Y, Akbaba G, et al. Association between C-reactive protein, carotid intimamedia thickness and $\mathrm{P}$-wave dispersion in obese premenopausal women: an observational study. Anadolu Kardiyol Derg 2012;12:40-6.

9. Yilmaz R, Demirbag R. P-wave dispersion in patients with stable coronary artery disease and its relationship with severity of the disease. J Electrocardiol 2005;38:279-84. CrossRef

10. Sullivan DR, Marwick TH, Freedman SB. A new method of scoring coronary angiograms to reflect extent of coronary atherosclerosis and improve correlation with major risk factors. Am Heart J 1990;119:1262-7. CrossRef

11. Gensini GG. Coronary arteriogaphy. Mount Kisco, New York: Futura Publishing Co, 1975.

12. Cameron A, Schwartz MJ, Kronmal RA, Kosinski AS. Prevalence and significance of atrial fibrillation in coronary artery disease (CASS Registry). Am J Cardiol 1988;61:714-7. CrossRef

13. Shimizu A, Centurion OA. Electrophysiological properties of the human atrium in atrial fibrillation. Cardiovasc Res 2002;54:302-14. CrossRef

14. Centurión OA, Shimizu A, Isomoto S, Konoe A. Mechanisms for the genesis of paroxysmal atrial fibrillation in the Wolff Parkinson-White syndrome: intrinsic atrial muscle vulnerability vs. electrophysiological properties of the accessory pathway. Europace 2008;10:294-302. CrossRef

15. Centurión OA. Clinical implications of the $\mathrm{P}$ wave duration and dispersion: relationship between atrial conduction defects and abnormally prolonged and fractionated atrial endocardial electrograms. Int J Cardiol 2009;134:6-8. CrossRef

16. Spach MS, Dolber PC. Relating extracellular potentials and their derivatives to anisotropic propagation at a microscopic level in human cardiac muscle. Evidence for electrical uncoupling of side-to-side fiber connections with increasing age. Circ Res 1986;58:356-71. CrossRef

17. Kostin S, Klein G, Szalay Z, Hein S, Bauer EP, Schaper J. Structural correlate of atrial fibrillation in human patients. Cardiovasc Res 2002;54:361-79. CrossRef

18. Röcken C, Peters B, Juenemann G, Saeger W, Klein HU, Huth $\mathrm{C}$, et al. Atrial amyloidosis: an arrhythmogenic substrate for persistent atrial fibrillation. Circulation 2002;106:2091-7. CrossRef

19. Frustaci A, Chimenti C, Bellocci F, Morgante E, Russo MA, Maseri A. Histological substrate of atrial biopsies in patients with lone atrial fibrillation. Circulation 1997;96:1180-4. CrossRef

20. Boldt A, Wetzel U, Lauschke J, Weigl J, Gummert J, Hindricks $\mathrm{G}$, et al. Fibrosis in left atrial tissue of patients with atrial fibril- lation with and without underlying mitral valve disease. Heart 2004;90:400-5. CrossRef

21. Ausma J, Wijffels M, Thoné F, Wouters L, Allessie M, Borgers M. Structural changes of atrial myocardium due to sustained atrial fibrillation in the goat. Circulation 1997;96:3157-63. CrossRef

22. Brundel BJ, Henning RH, Kampinga HH, Van Gelder IC, Crijns HJ. Molecular mechanisms of remodeling in human atrial fibrillation. Cardiovasc Res 2002;54:315-24. CrossRef

23. Dilaveris PE, Andrikopoulos GK, Metaxas G, Richter DJ, Avgeropoulou CK, Androulakis AM, et al. Effects of ischemia on $\mathrm{P}$ wave dispersion and maximum $\mathrm{P}$ wave duration during spontaneous anginal episodes. Pacing Clin Electrophysiol 1999;22:1640-7. CrossRef

24. Ozmen F, Atalar E, Aytemir K, Ozer N, Açil T, Ovünç K, et al. Effect of balloon-induced acute ischaemia on $\mathrm{P}$ wave dispersion during percutaneous transluminal coronary angioplasty. Europace 2001;3:299-303. CrossRef

25. Turkmen M, Barutcu I, Esen AM, Karakaya O, Esen O, Basaran Y. Effect of slow coronary flow on P-wave duration and dispersion. Angiology 2007;58:408-12. CrossRef

26. Lammers WJ, Kirchhof C, Bonke FI, Allessie MA. Vulnerability of rabbit atrium to reentry by hypoxia. Role of inhomogeneity in conduction and wavelength. Am J Physiol 1992;262:H47-55.

27. Anderson KR, Sutton MG, Lie JT. Histopathological types of cardiac fibrosis in myocardial disease. J Pathol 1979;128:79-85.

28. Michelucci A, Bagliani G, Colella A, Pieragnoli P, Porciani MC, Gensini G, et al. P wave assessment: state of the art update. Card Electrophysiol Rev 2002;6:215-20. CrossRef

29. Cha YM, Dzeja PP, Shen WK, Jahangir A, Hart CY, Terzic A, et al. Failing atrial myocardium: energetic deficits accompany structural remodeling and electrical instability. Am J Physiol Heart Circ Physiol 2003;284:H1313-20.

30. Tükek T, Akkaya V, Demirel S, Sözen AB, Kudat H, Atilgan D, et al. Effect of Valsalva maneuver on surface electrocardiographic $\mathrm{P}$-wave dispersion in paroxysmal atrial fibrillation. Am J Cardiol 2000;85:896-9, A10.

31. Gunduz H, Binak E, Arinc H, Akdemir R, Ozhan H, Tamer A, et al. The relationship between $\mathrm{P}$ wave dispersion and diastolic dysfunction. Tex Heart Inst J 2005;32:163-7.

32. Chen YJ, Chen SA, Tai CT, Yu WC, Feng AN, Ding YA, et al. Electrophysiologic characteristics of a dilated atrium in patients with paroxysmal atrial fibrillation and atrial flutter. J Interv Card Electrophysiol 1998;2:181-6. CrossRef

33. Aytemir K, Ozer N, Atalar E, Sade E, Aksöyek S, Ovünç K, et al. $\mathrm{P}$ wave dispersion on 12-lead electrocardiography in patients with paroxysmal atrial fibrillation. Pacing Clin Electrophysiol 2000;23:1109-12. CrossRef

34. Magnani JW, Mazzini MJ, Sullivan LM, Williamson M, Ellinor PT, Benjamin EJ. P-wave indices, distribution and quality control assessment (from the Framingham Heart Study). Ann Noninvasive Electrocardiol 2010;15:77-84. CrossRef 